\title{
Ultrasound evaluation of the striated urethral sphincter as a predictive parameter of urinary continence after radical prostatectomy
}

\author{
Lucio Dell'Atti \\ Department of Urology, University Hospital "St.Anna”, Ferrara, Italy.
}

\begin{abstract}
Summary Objectives: The purpose of this study was to evaluate preoperatively the results of transrectal ultrasound (TRUS) in the detection of morphological, vascularization status of urethral rhabdosphincter (RS) and evaluate the correlation with urinary continence after radical prostatectomy ( $R P)$.

Methods: 211 patients who underwent RP were prospectively studied using TRUS scan of the RS thickness. At the end of the examination a study was performed with the use of colour-Doppler for the assessment of the RS vascularity pattern. The level of continence was graded on a 5 point scale as: 1 = complete continence, 2 = 1 pad daily, 3 = 2-3 pads daily, $4=4$ or more pads daily, and $5=$ complete incontinence. Results: It was possible to visualize the rhabdosphincter and its vascularity in all patients. Patients with normal continence (level 1 and 2) showed a sphincter-muscle thickness of 3.5 $\mathrm{mm}( \pm 0.4)$ and a hypoechoic ultrasound pattern. With respect to the other levels 3,4 and 5 of urinary incontinence RS thickness was $2.8 \mathrm{~mm}( \pm 0.5), 2.1 \mathrm{~mm}( \pm 0.6), 1.7( \pm 0.7)$ respectively. Incontinence after $R P(\geq 3$ level) was associated with urethral sphincter deficiency in the great majority of patients. Statistical significant differences were observed in the vascularity between continent and incontinent men in all measured vascularity variables $(p<0.005)$.

Conclusions: This study suggests that RS integrity is a good predictor of urinary continence after RP and this information can be important during the preoperative phase as part of the informed consent.
\end{abstract}

KEY WORDS: Transrectal ultrasound; Urinary incontinence; Radical prostatectomy; Urethral sphincter.

Submitted 17 June; Accepted 30 September

\begin{abstract}
INTRODUCTION
Radical prostatectomy (RP) is the most common treatment for localised prostate cancer. Urinary incontinence (UI) is one of the most disturbing aftereffects of RP (1). Postoperative UI has a negative effect on the health-related quality of life after RP (2). In literature some authors analysed the influence of perioperative factors (patient age, body mass index, and prostate volume), anatomic factors (trigonal denervation, puboperinealis musclesparing dissection, and preservation of endopelvic fascia), and technical factors (bladder neck preservation, mucosal eversion, urethral length preservation, neu-
\end{abstract}

rovascular bundle, and puboprostatic ligament preservation) as possible causes of urinary incontinence (2-5). In males, urethral sphincter is a cylindrical structure surrounding the urethra and extending vertically from bladder neck to perineal membrane, consisting of urethral smooth sphincter and urethral striated sphincter (6). Histomorphological studies demonstrated a separate external urethral sphincter, also termed rhabdosphincter (RS), in both men and women (7-9). Strasser $\mathrm{H}$ et al. (10) described this sphincter as an "omega-shaped" structure. The RS plays an important role in actively maintaining continence (11). The integrity and functional preoperative capacity of the urethral RS is a fundamental prerequisite of UI in men after RP. The purpose of this study was to evaluate the results of transrectal ultrasound (TRUS) in the detection of morphological, vascularization and preoperative functional status of urethral RS. Starting from this point of view, we used TRUS to determine the anatomical changes in urethral sphincter after $\mathrm{RP}$ and evaluated the correlation between these changes and postoperative urinary continence.

\section{MATERIALS AND METHODS}

Between September 2007 and December 2013, 211 consecutive patients who underwent RP (treated by three experienced operators: 76 with laparoscopic technique and 135 with open technique) were prospectively studied using 2-dimensional (2D) TRUS scan of the RS dimensions and vascularity. Patients who had neurogenic bladder, incontinence or urinary retention before prostatectomy were excluded. All procedures were performed in empty bladder, since we believe that even the state of bladder repletion may be an element of discomfort during the exam performance. Each patient was treated under local anesthesia with lidocaine spray (10 gr/100 $\mathrm{ml}$ ), applied two minutes before the procedure (12). TRUS was performed with the patient in the left lateral decubitus using a General Electric Logiq 7 machine equipped with a 5-9 $\mathrm{MHz}$ multi-frequency convex probe "end-fire". Each TRUS performed included an assessment of the prostatic diameter, the volume of the whole prostate, the transition zone, capsular and seminal vesicle characteristics, as well as morphological description of potential pathological features. This transducer pro-

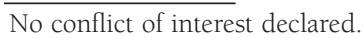


Figure 1.

Transrectal ultrasound in axial section of a continent patient with the urethra $(U)$ and rhabdosphincter (RS) presenting a hypoechoic incomplete band around the central core. The thickness of RS measures $3.6 \mathrm{~mm}$.

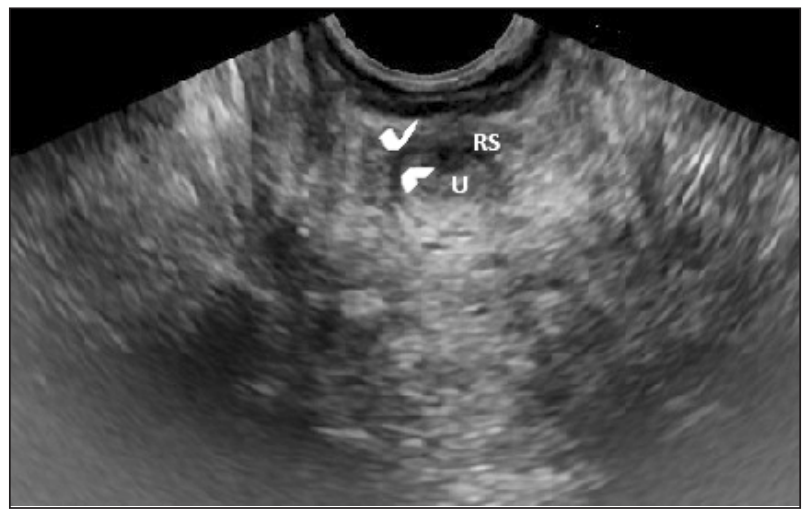

vides 2D sagittal and axial section of the posterior urethra and urethral sphincter complex. In males, urethral sphincter complex is a cylindrical structure surrounding the urethra and extending vertically from bladder neck to perineal membrane (inferior fascia of urogenital diaphragm), consisting of urethral smooth sphincter (presenting a hyperechogenic echostructure) and urethral RS (presenting a hypoechoic incomplete band around the central core). The striated urethral sphincter was clearly identified by its distinctive "omega-shaped" configuration and its hypoechoic ultrasound (US) pattern (6). The distance between urethra and the clearly demarcated inner contour of the sphincter was measured. The measurement points were aligned to the middle of the omega contour of the sphincter (Figure 1). At the end of the examination a study was performed with the use of colour-Doppler (CD) mode for the assessment of the urethral and RS vascularity pattern, both in sagittal and axial sections. The examination technique was standardized to an exact protocol that also included the execution of TRUS to determine anatomical changes in urethra after RP in incontinent patients. All patients were studied with 2D-TRUS pre and post-operatively by a single experienced surgeon in urologic ultrasound. Informed consent for this study design was obtained from each patient. All patients completed a postoperative questionnaire on urinary function and were followed up for 12 months postoperatively. The level of stable continence was graded on a 5 point scale as: 1 = complete continence, $2=1$ pad daily, $3=2-3$ pads daily, $4=4$ or more pads daily, and 5 = complete incontinence. The removal of the catheter and the teaching of pelvic floor exercises have been applied for 9 days after surgery. Time to stable continence after surgery was measured in months and the percentages of patients regaining urinary continence at 3, 6 and 12 months after catheter removal were assessed. All patients incontinent at 12 months were subjected to urethroscopy and urodynamic study, excluding the presence of postoperative stenosis or overactive bladder.

\section{Statistical analysis}

Comparison of quantitative (follow-up time, age, prostate volume, prostatic specific antigen [PSA]) and categoric (pathologic stage, Gleason) variables between group of continent patients and group of incontinent patients were performed with the use of Mann-Whitney $U$ and chi-square tests, respectively. The level of statistical significance was set at $\mathrm{p}<0.005$.

\section{RESULTS}

Clinical and pathological characteristics of our 211 patients have been summarized in Table 1. No significant difference was noted between the groups ( $\mathrm{A}=$ continent group and $\mathrm{B}=$ incontinent group) when comparing age, preoperative PSA level, prostate volume, Body Mass Index (BMI), clinical stage and Gleason grade.

Continence was regained in 188 (89.1\%) patients (group A), while incontinence ( $\geq 3$ level of questionnaire) was noted in 23 (10.9\%) patients at 3, 6 and 12 months following the catheter removal. Twenty-three patients remained incontinent with a level $\geq 3$, of which: 16 level 3, 4 level 4, and 3 level 5. The median follow-up period for patients incontinent was 12.3 months. 2D TRUS proved an accurate imaging technique for RS visualization. It was possible to visualize the rhabdosphincter in all patients, and the vascularity of this structure was clearly observed. The omega-shaped muscular loop presents as a hypoechoic structure surrounding the membranous urethra at its ventral and lateral aspects. Patients with normal continence ( 1 and 2 questionnaire levels) showed a sphincter-muscle thickness of $3.5 \mathrm{~mm}$ $( \pm 0.4)$ and a hypoechoic US pattern.

\section{Table 1.}

Clinical and pathological characteristics of patients.

\begin{tabular}{|c|c|c|c|}
\hline $\begin{array}{l}\text { Patients } \\
\text { characteristics }\end{array}$ & $\begin{array}{c}\text { Continent } \\
\text { group } \\
(n=188)\end{array}$ & $\begin{array}{c}\text { Incontinent } \\
\text { group }(\geq 3 \text { level) } \\
(n=23)\end{array}$ & p-value \\
\hline Age at diagnosis (yrs) (mean): & $68.5(56-76)$ & $69.7(57-74)$ & NS \\
\hline Mean preoperative PSA (ng/ml): & $6.8(2.1-17)$ & $6.1(1.2-15)$ & NS \\
\hline Mean prostate volume (cc): & $48.2(19-115)$ & $51.6(21-98)$ & NS \\
\hline $\begin{aligned} \text { Body Mass Index } & \left(\mathrm{kgm}^{2}{ }^{2}\right)(\%): \\
& <18.5-24.9 \\
& 25.0-29.9 \\
& >30.0\end{aligned}$ & $\begin{array}{l}35(18.6) \\
56(29.8) \\
97(51.6)\end{array}$ & $\begin{array}{c}4(17.4) \\
8(34.8) \\
11(40.3)\end{array}$ & NS \\
\hline $\begin{array}{r}\text { Clinical stage n. (\%): } \\
\mathrm{T} 1 \\
\geq \mathrm{T} 2\end{array}$ & $\begin{array}{c}49(26.1) \\
139(73.9)\end{array}$ & $\begin{array}{c}7(30.5) \\
16(69.5)\end{array}$ & NS \\
\hline $\begin{array}{l}\text { Pathological Gleason score n. (\%): } \\
\qquad 6 \\
7 \\
\geq 8\end{array}$ & $\begin{array}{c}103(54.8) \\
69(36.7) \\
16(8.5)\end{array}$ & $\begin{array}{c}13(56.5) \\
7(30.5) \\
3(13)\end{array}$ & NS \\
\hline $\begin{aligned} \text { Type of surgery } & \text { n. (\%): } \\
& \text { Open } \\
& \text { Laparoscopic }\end{aligned}$ & $\begin{array}{c}120(63.8) \\
68(36.2)\end{array}$ & $\begin{array}{c}15(65.2) \\
8(34.8)\end{array}$ & NS \\
\hline Median follow-up (months) & $11.9(6-12)$ & $12.3(6-12)$ & NS \\
\hline Intraoperative complications n. (\%) & ): $7(3.7)$ & $1(4.3)$ & NS \\
\hline Postoperative complication n. (\%): & $8(4.2)$ & $1(4.3)$ & NS \\
\hline
\end{tabular}




\section{Figure 2.}

Transrectal ultrasound in axial section of an incontinent patient (level 5) with rhabdosphincter (RS) presenting an inhomogeneous US pattern. The thickness of RS measures $1.9 \mathrm{~mm}$ [arrows].

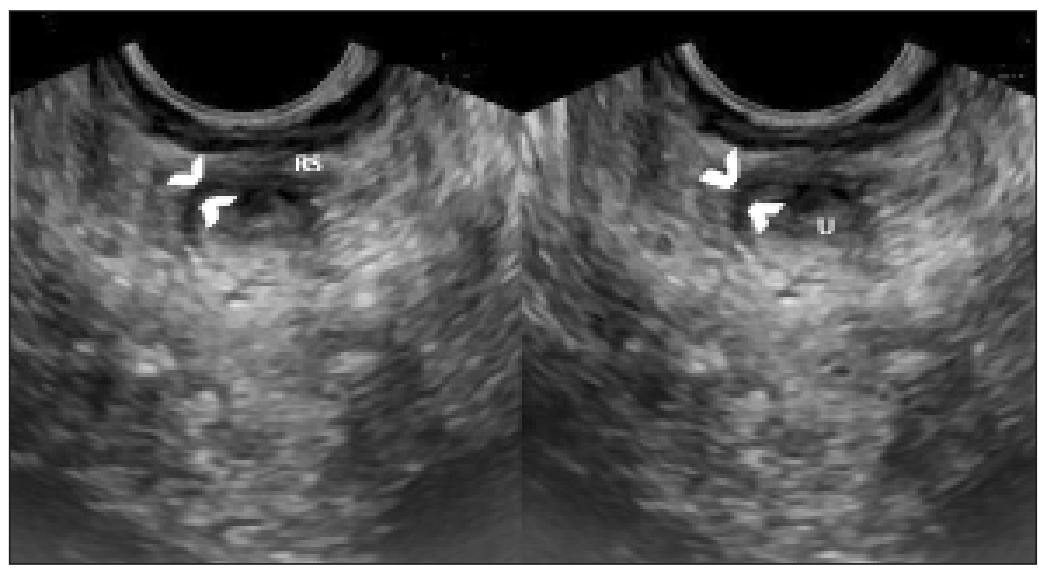

vascularity between continent and incontinent men in all measured vascularity variables (Figure 3). There was no statistically significant difference in patients of the incontinent group depending on the different surgical approach used ( $\mathrm{p}=$ 0.246). Also regarding intraoperative (excessive bleeding, prolonged operative time, and presence of surgical adhesions) and postoperative complications (presence of hematoma or lymphocele), the two groups did not reach a statistical significance $(\mathrm{p}=0.034)$.

Overactive bladder was showed in one patient of 4 level. Bladder-neck strictures occurred in five patients $(2.7 \%)$ of group A 6 months after catheter removal and in four patients (2.2\%) 12 months after catheter removal.
Table 2.

2-dimensional and colour Doppler Transrectal Ultrasound (TRUS) results.

\begin{tabular}{|c|c|c|c|}
\hline TRUS results & $\begin{array}{l}\text { Continent } \\
\text { group } \\
(n=188)\end{array}$ & $\begin{array}{c}\text { Incontinent } \\
\text { group }(\geq 3 \text { level) } \\
(n=23)\end{array}$ & p-value \\
\hline $\begin{array}{l}\text { Preoperative RS thickness mean } \\
\pm \mathrm{SD},(\mathrm{mm}) \text { : }\end{array}$ & $3.5 \mathrm{~mm}(0.4)$ & $2.3(0.5)$ & $<0.001$ \\
\hline $\begin{array}{l}\text { RS ultrasound pattern n. (\%): } \\
\text { hypoechoic echogenicity }\end{array}$ & $181(96.2 \%)$ & $9(39.1 \%)$ & $<0.005$ \\
\hline inhomogeneous echogenicity & $7(3.8 \%)$ & $14(60.9 \%)$ & $<0.005$ \\
\hline $\begin{array}{l}\text { RS axial FV mean } \pm S D \text {, } \\
\text { (cm/sec): }\end{array}$ & $0.41(0.13)$ & $0.19(0.07)$ & $<0.001$ \\
\hline RS axial A mean \pm SD: & $0.06(0.05)$ & $0.02(0.01)$ & $<0.001$ \\
\hline RS axial RI mean \pm SD: & $0.88(0.14)$ & $0.99(0.05)$ & $<0.005$ \\
\hline RS axial PI mean $\pm S D$ : & $2.13(1.19)$ & $3.25(1.46)$ & 0.01 \\
\hline $\begin{array}{l}\text { RS sagittal FV mean } \pm S D \text {, } \\
\text { (cm/sec): }\end{array}$ & $0.39(0.1)$ & $0.18(0.09)$ & $<0.001$ \\
\hline RS sagittal A mean $\pm S D$ : & $0.1(0.05)$ & $0.02(0.02)$ & $<0.001$ \\
\hline RS sagittal RI mean $\pm S D$ : & $0.78(0.23)$ & $0.98(0.04)$ & $<0.001$ \\
\hline RS sagittal PI mean \pm SD: & $1.84(0.24)$ & $2.89(1.32)$ & $<0.001$ \\
\hline
\end{tabular}

In the other levels of urinary incontinence (3, 4 and 5) RS thickness was $2.8 \mathrm{~mm}( \pm 0.5), 2.1 \mathrm{~mm}( \pm 0.6), 1.7$ ( \pm $0.7)$ respectively (Figure 2 ).

Incontinence after RP ( $\geq 3$ level) was associated with urethral sphincter deficiency in the overwhelming majority of patients.

Furthermore in the continent group an inverse relation was observed between the thickness of RS and the time required to reach the stable continence. In seven patients of level 3, in all patients of level 4 and in three patients with complete incontinence (level 5) the sphincter-muscle was noted as inhomogeneous echogenicity. CD analysis showed reproducible results for both axial and sagittal plane parameters (Table 2).

Statistical significant differences were observed in the

\section{Discussion}

The RS of the adult male is a muscular coat ventral and lateral to the membranous urethra and prostate, the core of which is an omega-shaped loop around the urethra. The sphincter-loop is continuous with muscle bundles which run along the anterior and lateral side of the prostate and extend cranially until they reach the bladder neck $(13,14)$. A number of studies have discussed a variety of risk factors that influence UI following RP. Identification of the reliable risk factors may aid in the prevention of postoperative UI and selection of patients. However, substantial controversy exists regarding the risk factors $(1,5,10)$. Preoperatively, the patient's age, urinary function, detrusor status, prostate volume, bladder capacity, and compliance are known.

Intraoperatively, the surgical technique and degree of preservation of the neurovascular bundles have been

\section{Figure 3.}

Transrectal ultrasound in axial section with the use of colour Doppler in an incontinent patient (level 5) with rhabdosphincter (RS) presenting poor vascularization.

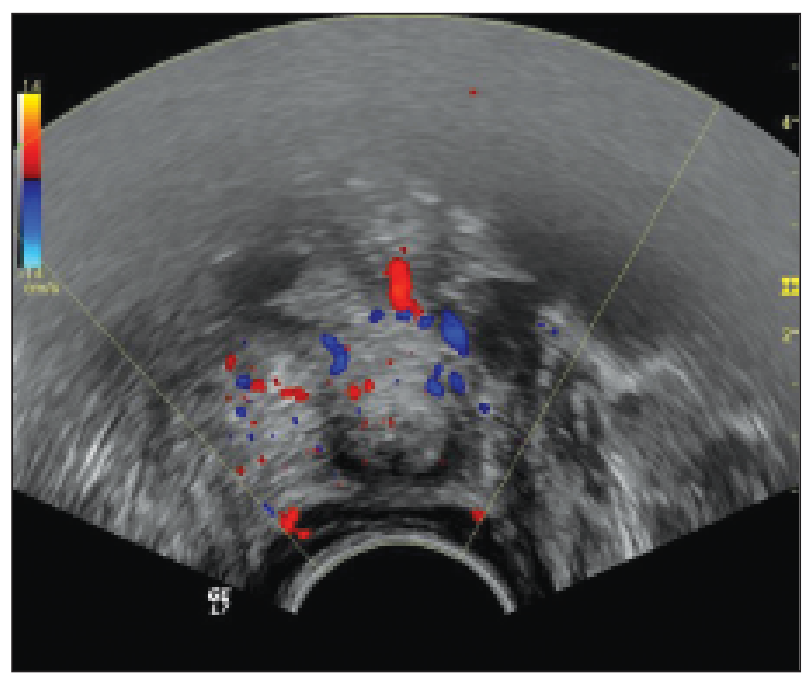


shown as independent predictors of long term urinary continence (15). In this study, we examined the possible relationship between preoperative anatomic integrity of RS (in terms of thickness and vascularity) and UI after RP. Several studies emphasized the significance of maximizing urethral length for favourable urinary control after RP. Myers et al. (16) examined the anatomy of the male pelvic floor before undergoing RP and defined the anatomy, sphincter urethral length, levator ani muscles, puboprostatic ligaments and their anatomic relations. They calculated the mean sphincter urethral length as 21 $\mathrm{mm}$ (range 15-24 $\mathrm{mm}$ ) in midline sagittal images and 20 $\mathrm{mm}$ (15-24 mm) from coronal images and recommended various operative methods for maintaining the length of urethral stump to achieve in urinary continence after RP. Similarly Coakley et al. (17) reported the mean sphincter urethral length before they underwent RP. They also reported that when a threshold of $12 \mathrm{~mm}$ was selected, $23-26 \%$ of patients with a preoperative urethral length of $12 \mathrm{~mm}$ or less were at least partially incontinent 1 year after surgery compared with $11 \%$ with a length of greater than $12 \mathrm{~mm}$. Unlike other authors, Strasser et al. (18) examined the RS of male urethra in 77 patients with urinary incontinence after transurethral resection of the prostate or RP. They detected defects and postoperative scarring in the majority of the patients with postoperative urinary stress incontinence.

Furthermore, the patients presented with thinning in parts of the muscle and atrophy of the RS. Certain authors measured RS using urodynamic assessment (8, 19). In other studies RS was examined using endorectal magnetic resonance imaging $(9,20,21)$ or intraurethral US (22). However, to the best of our knowledge, no studies are currently available regarding the measurement of RS in terms of thickness and vascularity by preoperative 2D TRUS. Statistical significant differences were observed in the US pattern and vascularity between continent and incontinent patients. However, there was no statistically significant difference between the two groups depending on the different surgical approach used. Several limitations need to be acknowledged. A first limitation of our study concerns the race: the participants are white, therefore results might not be extended to other races. The size of the cohort was small, making it difficult to statistically identify variables, such as RS thickness or vascularity, that may have a clinical significant effect on continence. RS and its vascularity measured with endorectal US and assessed with our personal definition cannot still be considered as a standard diagnostic modality. Further studies with a larger cohort will be useful to confirm this classification. Finally, the median follow-up time of 12 months turned out to be insufficient, so that further studies with a longer follow-up are necessary. This study suggests that RS integrity is a good predictor of urinary continence after RP and this information can be important during the preoperative phase as part of the informed consent.

\section{Conclusions}

In conclusion, 2D TRUS permits direct assessment of the integrity and vascularity of RS by means of a newly defined quantitative parameter. According to our preliminary results, in contrast to the other studies which mentioned the importance of preoperative sphincter urethral length in regaining continence after RP, preoperative thickness and vascularity RS may not be the sole important factor for urinary incontinence after RP. In the future, the studies that include measurements of preoperative measurements of RS in continent and incontinent patients might help to solve the important factors likely to contribute to postoperative continence after RP.

\section{RefEREnCES}

1. De Carlo F, Celestino F, Verri C, et al. Retropubic, laparoscopic, and robot-assisted radical prostatectomy: surgical, oncological, and functional outcomes: a systematic review. Urol Int. 2014; 93:373-383

2. Ganzer R, Stolzenburg JU, Neuhaus J, et al. Is the striated urethral sphincter at risk by standard suture ligation of the dorsal vascular complex in radicalprostatectomy? An anatomic study. Urology. 2014; 84:1453-1460.

3. Majoros A, Bach D, Keszthelyi A, et al. Analysis of risk factors for urinary incontinence after radical prostatectomy. Urol Int. 2007; 78:202-207.

4. Cambio AJ, Evans CP. Minimising postoperative incontinence following radical prostatectomy: considerations and evidence. Eur Urol. 2006; 50:903-913.

5. Rocco F, Carmignani L, Acquati P, et al. Early continence recovery after open radical prostatectomy with restoration of the posterior aspect of the rhabdosphincter. Eur Urol. 2007; 52:376-383.

6. Wang XD, Liu S, Xiong LX, et al. Normal anatomy of urethral sphincter complex in young Chinese males on MRI. Int Urol Nephrol. 2014; 46:1469-1476.

7. Strasser H, Klima G, Poisel S, et al. Anatomy and innervation of the rhabdosphincter of the male urethra. Prostate. 1996; 28:24-31.

8. Porena M, Mearini E, Mearini L, et al. Voiding dysfunction after radical retropubic prostatectomy: more than external urethral sphincter deficiency. Eur Urol. 2007; 52:38-45.

9. Haga N, Ogawa S, Yabe M, et al. Association between postoperative pelvic anatomic features on magnetic resonance imaging and lower tract urinary symptoms after radical prostatectomy. Urology. 2014; 84:642-649.

10. Strasser H, Frauscher F, Helweg G, et al. Transurethral ultrasound: evaluation of anatomy and function of the rhabdosphincter of the male urethra. J Urol. 1998; 159:100-104.

11. Hinata N, Murakami G, Miyake H, et al. Urethral sphincter fatigue after robot-assisted radical prostatectomy: descriptive questionnaire-based study and anatomic basis. Urology. 2014; 84:144-148.

12. Dell'Atti L, Daniele C. Lidocaine spray administration during transrectal ultrasound guided prostate biopsy modified the discomfort and pain of the procedure: results of a randomized clinical trial. Arch Ital Urol Androl. 2010; 82:125-127.

13. Steiner MS, Morton RA, Walsh PC. Impact of anatomical radical prostatectomy on urinary continence. J Urol. 1991; 145:512514.

14. Zvara P, Carrier S, Kour NW, Tanagho EA. The detailed neuroanatomy of the human striated urethral sphincter. Br J Urol. 1994; 74:182-187. 
15. Myers RP. Male urethral sphincteric anatomy and radical prostatectomy. Urol Clin North Am. 1991; 18:211-227.

16. Myers RP, Cahill DR, Devine RM, King BF. Anatomy of radical prostatectomy as defined by magnetic resonance imaging. J Urol. 1998; 159:2148-2158.

17. Coakley FV, Hricak H. Radiologic anatomy of the prostate gland: a clinical approach. Radiol Clin North Am. 2000; 38:15-30.

18. Strasser H, Pinggera GM, Gozzi C, et al. Three-dimensional transrectal ultrasound of the male urethral rhabdosphincter. World J Urol. 2004; 22:335-338.

19. Kleinhans B, Gerharz E, Melekos M, et al. Changes of urodynamic findings after radical retropubic prostatectomy. Eur Urol. 1999; 35:217-221.
20. Coakley FV, Eberhardt S, Kattan MW, et al. Urinary continence after radical retropubic prostatectomy: relationship with membranous urethral length on preoperative endorectal magnetic resonance imaging. J Urol. 2002; 168:1032-1035.

21. Paparel P, Akin O, Sandhu JS, et al. Recovery of urinary continence after radical prostatectomy: association with urethral length and urethral fibrosis measured by preoperative and postoperative endorectal magnetic resonance imaging. Eur Urol. 2009; 55:629-637.

22. Frauscher F, Helweg G, Strasser H, et al. Intraurethral ultrasound: diagnostic evaluation of the striated urethral sphincter in incontinent females. Eur Radiol. 1998; 8:50-53.

\section{Correspondence}

Lucio Dell'Atti, MD, PhD. (Corresponding Author)

dellatti@hotmail.com

Department of Urology

University Hospital "St.Anna".

8 A. Moro Street 44124 Cona, Ferrara, Italy 